International Journal of Biology, Pharmacy and Allied Sciences (IJBPAS)

'A B Bridge Betusen Caboratory and QRendo'

WwW.iibpas.com

\title{
MERALGIA PARESTHETICA IN PREGNANCY
}

\author{
ALI SABRI ${ }^{1}$ AND ZAID AL-ATTAR ${ }^{2 *}$ \\ 1: Rheumatologist in Rheumatology Specialist Clinic in Al-Kindy Teaching Hospital / \\ Baghdad
}

2: Lecturer Dept. of pharmacology, Al-Kindy College of Medicine / University of Baghdad *Corresponding Author: E Mail: zaidattar@kmc.uobaghdad.edu.iq; Tel: +9647711827558

Received $17^{\text {th }}$ Oct. 2018; Revised $16^{\text {th }}$ Nov. 2018; Accepted $23^{\text {rd }}$ Nov. 2018; Available online $1^{\text {st }}$ April 2019

\section{https://doi.org/10.31032/IJBPAS/2019/8.4.4679}

\section{ABSTRACT}

Objective: To study the association between pregnancy and meralgia.

paresthetica (MP), the entrapment neuropathy of the lateral femoral cutaneous nerve $(\mathrm{LFCN})$.

Methods: Three hundred and forty pregnant women were surveyed by history and clinical examination in 3 major Obstetric Centers in Baghdad for the presence of underlying MP and compared to a control group of 200 non-pregnant females.

Results: Thirteen pregnant women were found to have MP (3.8\%) in contrast to only one out of 200 non-pregnant women in the control group $(0.5 \%)$, which was significant statistically $(\mathrm{P}=0.019)$.

Most of the cases were in their third trimester $(53.8 \%)$, then in the second trimester $(38.5 \%)$, while only $7.7 \%$ of cases in the first trimester.

Conclusion: MP in pregnancy is not a rare disorder but is often misdiagnosed. The etiological factors in pregnancy may be mechanical and/or anatomical variations of the LFCN. However, this study disproves neither a hormonal nor a hereditary role in the causation of the disorder.

Keywords: Meralgia paresthetica, pregnancy, neuropathy, femoral nerve 


\section{INTRODUCTION}

Meralgia paresthetica (MP) is an entrapment neuropathy of the lateral cutaneous nerve of the thigh related to its compression in the region of the anterior superior iliac spine (ASIS) [1].

This condition was first recognized by Hager 1n 1885. Bernhardt in 1895 described five unilateral cases of the condition, all of which affected middle aged men. Later that year Roth introduced the term "Meralgia paresthetica", although it was also referred to as "Bernhardt's disturbance of sensation" [2].

The lateral femoral cutaneous nerve (LFCN) arises from the posterior division of the second and third lumbar segments, it emerges from under the psoas major and runs on the iliacus muscle to reach the ASIS, it then runs under the outer end of the inguinal ligament to reach the thigh. It divides into anterior and posterior branches which pierce the fascial at a about 4 inches below the ASIS and the terminal branches reach down to the knee [3 \& 4].

Many authors have defined the condition as rare or uncommon while others have defined it as common but often overlooked or misdiagnosed [5]. It is predominantly a disease of males [ $6 \&$ 7] and is seen more commonly in people who have diabetes, are pregnant, or are obese [8].
Direct trauma, compression from a corset, or leg-length discrepancy may also be factors in developing MP.

However, the clinical signs and symptoms are very similar in most cases, mostly in the form of a burning sensation and/or numbness over a large area in the anterolateral aspect of the thigh, but the neurological examination reveals objective sensory changes over a smaller area. The history alone, which is so typical is usually sufficient to establish a correct diagnosis, where the patient can fairly localize accurately the complained area, which follows the characteristic distribution of the LFCN, sometimes called the pocket area [5].

The aim of our study is to confirm the association of MP and define its prevalence, in pregnancy.

\section{PATIENTS AND METHODS}

Three hundred and forty pregnant women, their ages ranged from 18 to 43 years were involved in this cross-sectional study. They were attendants of Obstetrical Units of 3 major centers in Baghdad City (Baghdad Teaching Hospital, Saddam Teaching Hospital, and Al- Ilwiyah Hospital). The period of the study was from the 1st October 1999 till the 1st May 2005.

A pregnant woman was considered to 
suffer from MP if she had a burning pain and/or numbness over the antero-lateral aspect of the thigh that occurred in pregnancy. Positive cases were questioned regarding parity and age of gestation, and multipara were stressed historically about occurrence of similar features in previous pregnancies and its disappearance after delivery. In addition, our questionnaire included the affected side, severity, exacerbating and relieving factors, its relation to the menstrual cycle [9], and family history [10 \& 11].

The diagnosis was supported by reproduction of signs and symptoms by pressure application on the inguinal ligament just medial to the ASIS and by abduction and extension of hip joint, in addition to sensory changes (touch, pin prick) over the area of the LFCN distribution, and the absence of reflex and motor deficit [8].

The same clinical survey; excluding questions that are related to pregnancy, was applied to 200 non-pregnant control women, matched for age, who were attendants of the Dermatology Department.

We have excluded women with diabetes, backache (of upper lumbar root irritation) and trauma from the study.

Statistical analysis was done for the collected information by descriptive measures and using chi-square test, when needed, for the significance of difference.

\section{RESULTS}

Thirteen positive cases out of 340 pregnant women were found, i.e. general prevalence of MP in pregnancy in our study is $38 / 1000(3.8 \%)$ while only one case in controls was detected which was obese, 4lyears old; 5/1000 (0.5\%) (Table1). This difference was significant statistically $(\mathrm{P}=0.019)$.

The ages of cases ranged from 18 to 41 years (mean 29.8 \pm 7 years).

Most cases were in the third trimester, 7 patients $(53.8 \%)$, followed by second trimester, 5 patients $(38.50 / 0)$, then lastly the first trimester only one patient $(7.70 \%)$ as shown in figure 1.

Seven of the patients were multipara and 6 were primigravida (Fig. 2).

Eight women complained mainly of numbness with minimal pain and 5 complained of both pain and numbness, of the last group, only 2 mentioned affection severe enough to limit their activities.

The involvement was bilateral in 7 cases, right sided in 5 and left sided in one patient only (Table 2).

All patients experienced exacerbation of symptoms by prolonged standing and walking, and 10 of them experienced relief by lying supine.

Of the multiparous group ( 7 patients), 5 of 
them mentioned direct relation to

In all our patients, sensory examination pregnancy in the form of appearance of revealed primarily decreased touch symptoms repeatedly during the preceding sensation in the area of LFCN supply, pregnancy and their disappearance soon while pain sensation was affected only in a following delivery, while 2 experienced smaller central area, and it was lost their first attack of MP. completely in this central area in the two Pressure application on the inguinal patients with severe involvement.

ligament reproduced symptoms in all All pregnant women with MP gave no patients, while abduction/extension of hip family history of such condition. did so in 9 of them.

Table 1: The prevalence of MP in pregnant and non-pregnant women

\begin{tabular}{|c|c|c|c|}
\hline Group & No. of cases & Percentage & Total \\
\hline Pregnant women & 13 & 3.8 & 340 \\
\hline Non-pregnant women (control) & 1 & 0.5 & 200 \\
\hline
\end{tabular}

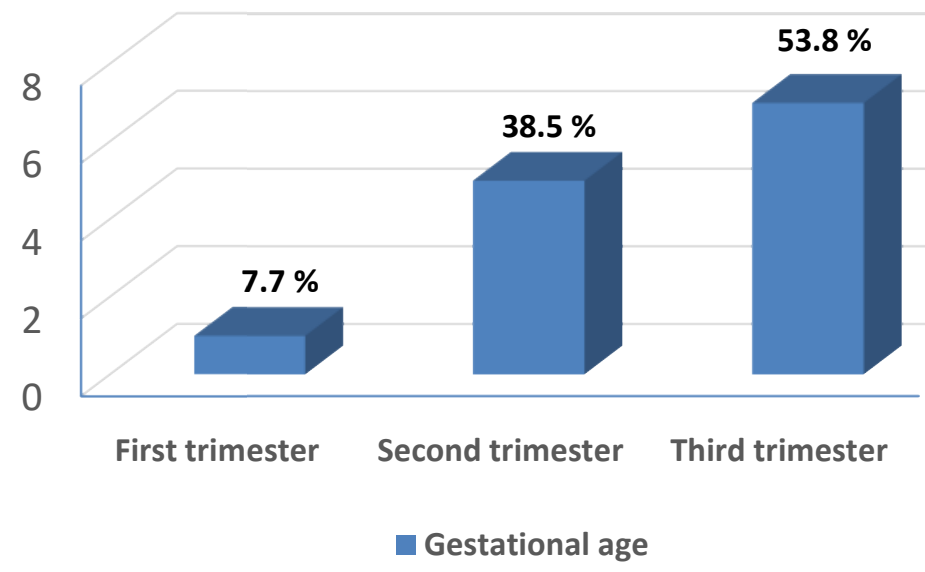

Figure 1: The distribution of cases according to gestational age

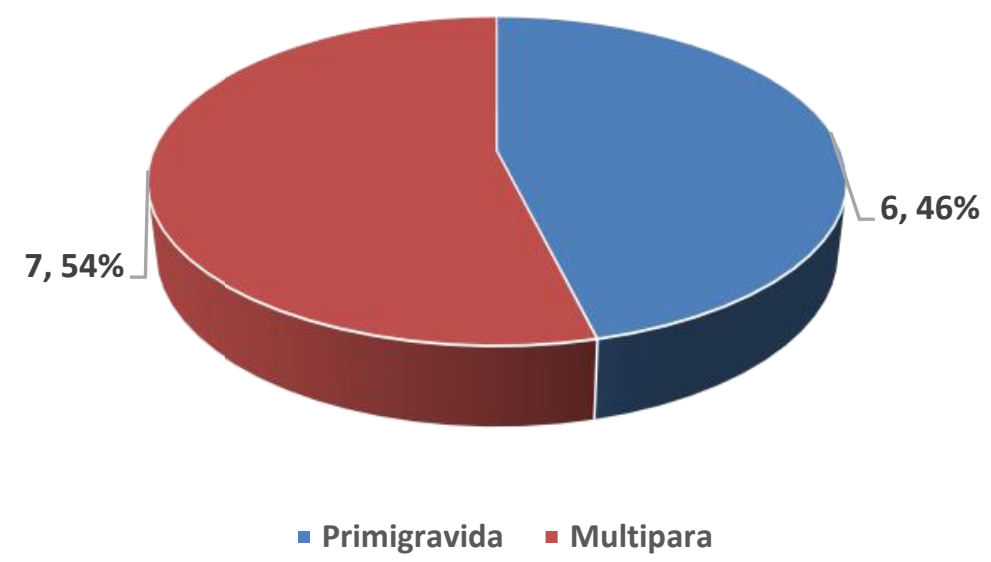

Figure 2: The distribution of cases according to parity 


\begin{tabular}{|c|c|c|c|c|}
\hline \multicolumn{2}{|c|}{ Character } & \multirow{3}{*}{\begin{tabular}{|c|}
$\begin{array}{c}\text { No. of } \\
\text { cases }\end{array}$ \\
8 \\
5
\end{tabular}} & \multirow{3}{*}{$\begin{array}{c}\% \\
61.5 \\
38.5\end{array}$} & \multirow{3}{*}{$\begin{array}{r}\text { Total } \\
13\end{array}$} \\
\hline \multirow{2}{*}{ Symptom } & Numbness & & & \\
\hline & Pain \& numbness & & & \\
\hline \multirow[t]{3}{*}{ Exacerbating factors } & Prolonged standing & 13 & 100 & \multirow{3}{*}{13} \\
\hline & Prolonged walking & 13 & 100 & \\
\hline & Lying supine & 10 & 76.9 & \\
\hline Recurrence with each pregnancy & & 5 & 71.4 & 7 \\
\hline \multirow{3}{*}{ Affected side } & Right & 5 & 38.5 & \multirow{3}{*}{13} \\
\hline & Left & 1 & 7.7 & \\
\hline & Bilateral & 7 & 53.8 & \\
\hline \multirow{2}{*}{$\begin{array}{c}\text { Pressure on inguinal ligament } \\
\text { Abduction and extension of hip joint }\end{array}$} & & 13 & 100 & \multirow{2}{*}{13} \\
\hline & & 9 & 69.2 & \\
\hline \multirow{3}{*}{ Sensory examination } & Hypoesthesia & 13 & 100 & \multirow{3}{*}{13} \\
\hline & Hypoalgesia & 11 & 84.6 & \\
\hline & analgesia & 2 & 15.4 & \\
\hline
\end{tabular}

\section{DISCUSSION}

The cause of the clinical symptoms in MP is irritation of the LFCN in the area around the ASIS. Many mechanisms of this irritation or compression have been suggested according to the anatomical variation in the route of the LFCN (Fig.3) [2].

The usual relationship is deep to the lateral end of the inguinal ligament but superficial to the sartorius muscle (main diagram). The nerve may (1) overlie the anterior iliac wing or (2) pass between two slips of the inguinal ligament, where entrapment is very likely. Below the inguinal ligament the nerve may (3) pass deep to or (4) through the sartorious and may (5) also be compressed distally when it passes through the deep fascia

The first study of MP in pregnancy was introduced by Rhodes in 1957, where a positive relationship was found [5].

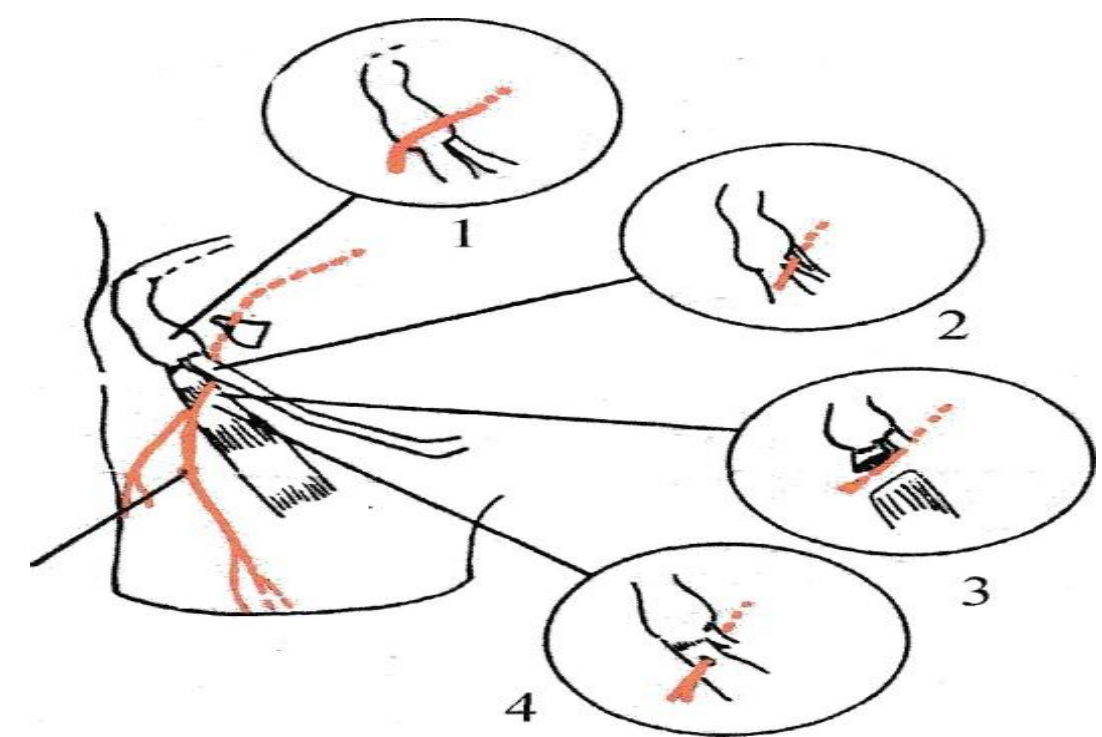

Fig. 3: The variation in the route and sites of compression of the lateral femoral cutaneous nerve 
Before that time, many hypotheses have been suggested to explain the occurrence of MP in general, that of Aird (1950) is the most attractive one as it also explains the positive association with pregnancy, as is the case in our study. He suggested that in some people the outer end of the inguinal ligament splits to enclose the nerve and that hyper extension of the hip causes the deep fasciculus to compress the nerve. Accordingly, the association of MP with pregnancy is explained by increased lumbarlordosis, increased pelvic inclination, and extension of hip in pregnant women. And the hypothesis may also account for the comparative scarcity of the cases as the symptoms depend on an anomaly of the inguinal ligament, present presumably in only a few women [5].

In contrast, Stookey (1928) in his study found that particular positions of the hip are not considered to affect the nerve significantly and he suggested that the sharp angulation of the LFCN as it leaves the pelvis subjects it to constant low-grade trauma [12].

Other suggested mechanism was that of Radvan \& Vidikan (1982) who supposed that entrapment of the LFCN of the thigh result from mechanical factors like stretching of the abdominal wall by any cause [13], while Deal \& Canosa (1982) explained the etiology as external compression of the nerve by the weight of the large abdomen [14].

In our study, and in congruence with Rhodes finding, there was a higher prevalence of MP in pregnant women $(3.8 \%)$ than in their age matched nonpregnant controls $(0.5 \%)$, and the condition was more frequent with advancing age of gestation i.e. $53.8 \%$ in third, $38.5 \%$ in the second, and $7.7 \%$ in the first trimesters.

Our opinion is that Aird's hypothesis for MP in pregnancy is relevant, in addition to the mechanical factors introduced by Radvan \& Vidikan and Deal \& Canosa.

The relative in frequency of MP in pregnancy may arouse the suggestion that the development of MP needs the presence of a mechanical factor in a susceptible person, i.e. for example, a person with an anatomical variation of the LFCN, a variation that was proved to occur in $25 \%$ of population by de-Ridder et. al., [15] in a postmortem study that included 200 recently deceased patients.

The increasing incidence with progressively enlarging abdominal size, together with lack of positive history of exacerbation during previous menstrual cycle are in favor of mechanical factors rather than hormonal factors that was suggested by Massey (1978) who mentioned a positive relationship of MP 
with menses and explained this result as a hormonal influence [9], a suggestion that may be confronted also by the male predominance of MP [6 \&7].

In contrast to Rhodes finding of only one out of 7 pregnant (14\%) with bilateral MP who was carrying a twins, careful history and examination in our series revealed that 7 out of $13(53.8 \%)$ complained of bilateral MP, though one side is more prominently involved.

No positive family history was reported by any of the 13 cases with MP, in contrast to Massey (1978) [11] and Malin (1979) [12] who suggested a familial occurrence of MP and an auto somal dominant mode of inheritance.

In the control group, only one woman $(0.5 \%)$ that was an obese lady aged 41 years and she was a mother of 3 children, showed a clinical picture suggestive of MP which she complained of intermittently for the last two years and she mentioned the presence of these symptoms before the last pregnancy, exacerbation during it and mild improvement, but not disappearance, of symptoms after delivery. Obesity here may be claimed as the inciting mechanical factor.

Pressure application over the course of the nerve appeared to bea more sensitive test for MP than abduction and extension of hips, and careful sensory examination revealed involvement of touch sensation in an oval area over the antero-lateral aspect of the thigh while pain sensation was impaired only in a smaller central area, and it was lost completely in this central area in only 2 patients. This finding goes with that of Ecker in 1985 [16].

In conclusion, MP is not an uncommon neurological complication of pregnancy, which may occasionally be severe and physically disabling, but usually disappear after delivery. Hormonal and hereditary factors appeared to play no clear role in the etiology of MP in pregnancy.

\section{REFERENCES}

[1]Jones RK. Meralgia paresthetica as a cause of legdis comfort. Can Med Assoc J 1974; 111:541-2.

[2]Macnicol MF, Thompson WJ. Idiopathic meralgia paresthetica. Clin Orthop 1990; 254:270-4.

[3]Rhodes P. Meralgia paresthetica in pregnancy. Lancet 1957; ii: 831.

[4]Snell RS. Clinical anatomy for medical students. $3^{\text {,d }}$ ed., Boston/Toronto, Little, Brown and Company, 1986:262.

[5]Moscona AR, Sekel R. Post-traumatic Meralgia paresthetica- an unusual presentation. J Trauma 1978; 18:288.

[6]Steven H. Meralgia paresthetica. Arch Neurol Psychiat 1957; 77:557-74.

[7]Bannister R. Disorders of nerve roots 
and peripheral nerves. In: Brain's clinical neurology. $6^{\text {th }}$ ed., Oxford, Oxford University

Press, 1987: 414.

[8]Joseph J, Biundo JR. Regional rheumatic pain syndromes. In: Klippel JH, Wey and CM, Wortmann RL,eds. Primer on the Rheumatic Diseases. $11^{\text {th }}$ ed., Atlanta, Georgia; Arthritis Foundation, 1997:136-48.

[9]Massey EW. Menstrual meralgia. Arch Neurol 1978; 35:541.

[10] Massey EW. Familial occurrence of meralgia paresthetica. Arch Neurol 1978; 35 (3):182.

[11] Malin JP. Familial meralgia paresthetica with an autosomal dominant trait. J Neurol., 1979; 221:133-6.

[12] Stookey B. Meralgia paresthetica: etiology and surgical treatment. JAMA 1928; 90:1705-7.

[13] Radvan GH, Vidikan P. Meralgia paresthetica and liver disease. Ann Intern Med 1982; 96:252-3.

[14] Deal CL, Canosa JJ. Meralgia paresthetica and large abdomens. Ann Intern Med 1982; 96:787.

[15] De-Ridder VA, de-Lange S, Popota JV. Anatomical variations of the lateral femoral cutaneous nerve and the consequences for surgery. $\mathrm{J}$ Orthop Trauma 1999; 13 (3): 207-11.
[16]Ecker AD. Diagnosis of Meralgia paresthetica. JAMA., 1985; 253:976. 